\title{
Backscattered Electrons Signal for Imunolocalization of Trypanosoma cruzi Surface Antigens
}

\author{
R.C.V. Pinto and T. Souto-Padrón
}

Laboratório de Biologia Celular e Ultraestrutura, Departamento de Microbiologia Geral, Instituto de Microbiologia Prof. Paulo de Góes - CCS - Bloco I - Universidade Federal do Rio de Janeiro CEP: 21941-590 - Rio de Janeiro, RJ - e-mail: souto.padron@micro.ufrj.br

Trypanosoma cruzi, the causative agent of Chagas'disease, is an obligate intracellular parasite. Throughout its life cycle, three distinct evolutive forms as much morphologically as physiologically are observed. Those evolutive forms need some kind of interaction with the host cell: epimastigotes, for example, bind to the insect digestive endothelium, the trypomastigote form interacts with the human host cells, and can be classified as metacyclic, which is excreted in the feces of the vector insect, and bloodstream form, which is liberated from previously infected cells. The intracellular form, amastigote, can also interact via its surface components just like the other forms. Previous studies have shown that the surface composition of those forms varies in accordance with the evolutive stage, and each stage presents characteristic features in chemical composition and molecular arrangement. The ultrastructure of $T$. cruzi has been studied previously with the electron microscope in thin sections. Although such studies may give important information concerning the organization of cellular components, they do not reveal details of the molecular distribution of surface antigens that might be acting on the process of interaction. For this purpose, we have used a high-resolution cold field emission scanning electron microscope equipped with detector for secondary and backscattered electrons (JEOL JSM-6340-F). The compositional (atomic number) contrast yielded from the detection of backscattered electrons allows studies using high atomic number tags, just like the colloidal gold, which has a stronger signal than the carbon main structure of common organic samples. Thus, the labeling profile may be compared with the topographic image (secondary electrons), allowing the co-localization with the cell surface domains of T. cruzi.

Trypomastigote forms were collected from the supernatant of previously infected cells (LLCMK2). After washing in PBS, the parasites were pre-fixed in solution containing formaldehyde 4\%, glutaraldehyde grade I $0.1 \%$, sucrose $3.7 \%$ in phosphate buffer $0.1 \mathrm{M}, \mathrm{pH} 7.2$, for one hour. The cells were, then, adhered on a silicon support by way of poly-L-lysine, and incubated with the primary anti-body (serum anti-SAPA, $80 \mathrm{kDa}$, LPPG and $\alpha$-GAL), followed by the secondary anti-body complexed with colloidal gold of $10 \mathrm{~nm}$. Another fixative was used, containing formaldehyde 4\%, glutaraldehyde grade II $2.5 \%$, sucrose $3.7 \%$ in cacodylate buffer $0.2 \mathrm{M}, \mathrm{pH} 7.2$. The samples were post-fixed in a solution of $1 \% \mathrm{OsO}_{4}, 0.8 \%$ potassium ferrocyanide and $5 \mathrm{mM}$ calcium chloride diluted in cacodylate buffer, for one hour. At last, the samples were dehydrated in ethanol, criticalpoint-dried, carbon coated and observed in a JEOL JSM-6340-F FESEM operating at 5kV.

It was possible to observe the distribution of gold particles throughout the cell body (Fig. 1, 27.000 $\mathrm{X})$. Interestingly, broad and slender trypomastigotes have not shown the same labeling profile for all the antibodies tested. Low voltage imaging allowed us to precisely localize the gold particles on the different domains on the surface of the parasite.

Financial support: CNPq, Pronex, Faperj, FUJB and CAPES 


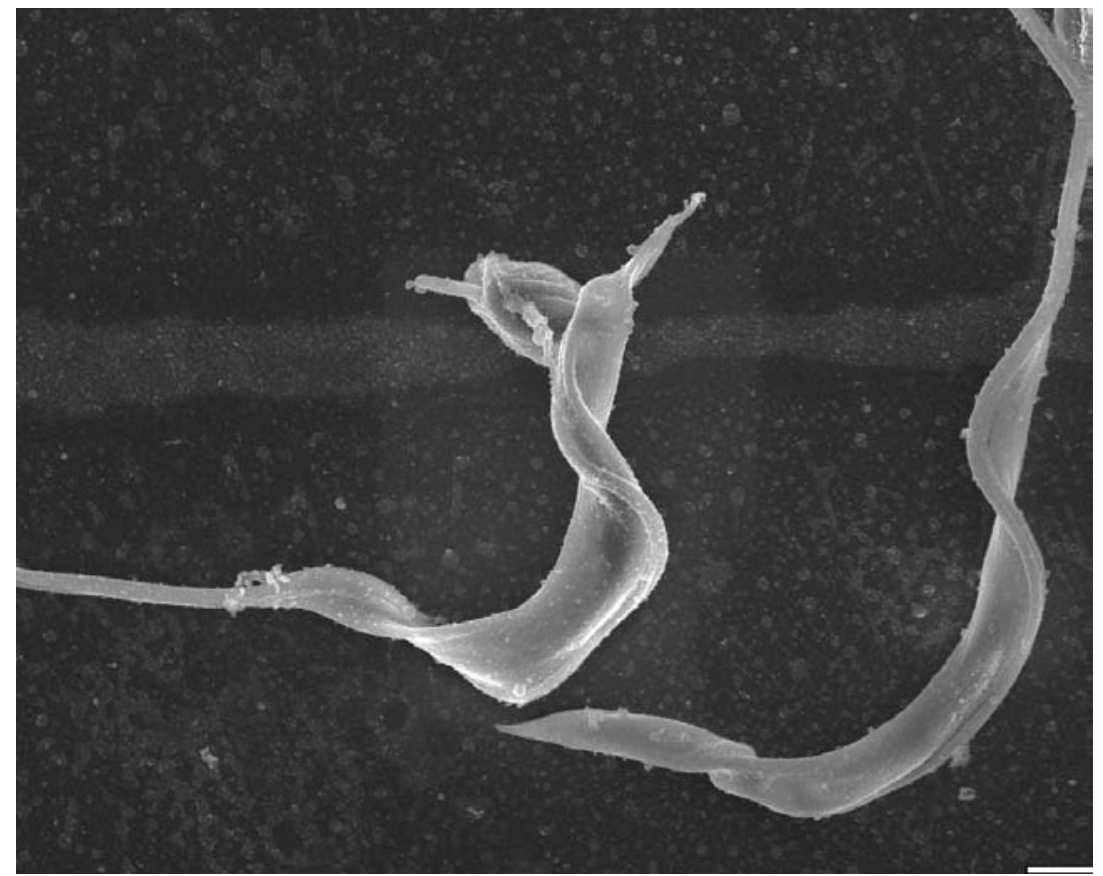

Fig. 1: Broad and Slender Trypomastigote from CL-Brener clone. Bar: $1 \mu \mathrm{m}$.

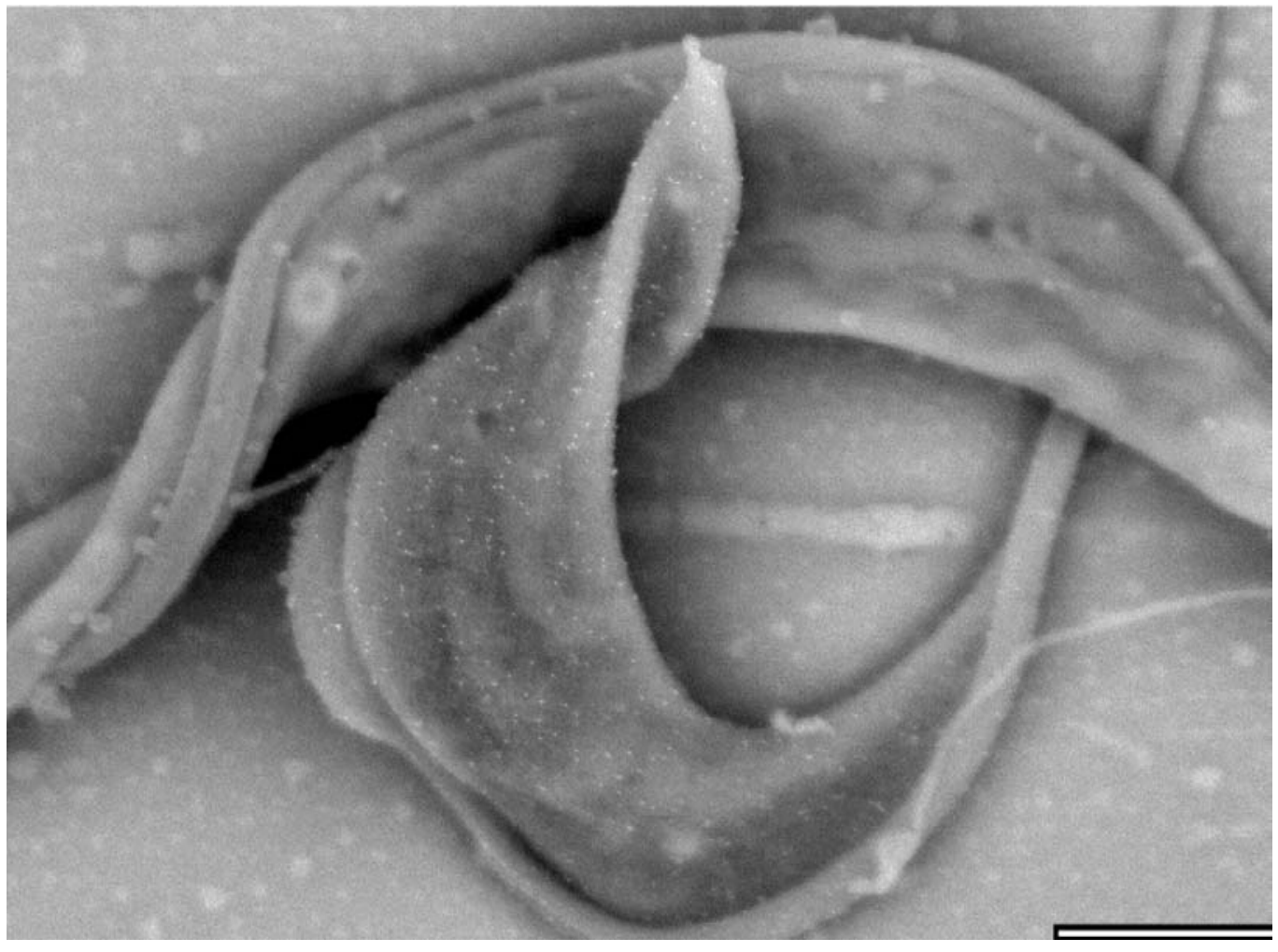

Fig. 2: Broad and Slender Trypomastigote from CL-Brener clone labeled with anti-80kDa. Bar: $1 \mu \mathrm{m}$. 